\title{
Corrigendum: Nucleotide recognition by the cytoplasmic domain of the human chloride transporter $\mathrm{ClC}-5$
}

Sebastian Meyer, Sara Savaresi, Ian C Forster \& Raimund Dutzler

Nature Structural \& Molecular Biology 14, 60-67 (2007); published online 31 December 2006; corrected after print 19 January 2007

In the version of this article initially published, Figure 4 contained an error. The legend labels placed within Figure $4 \mathbf{d}$ were exchanged. The corrected figure is shown here. The error has been corrected in the HTML and PDF versions of this article.

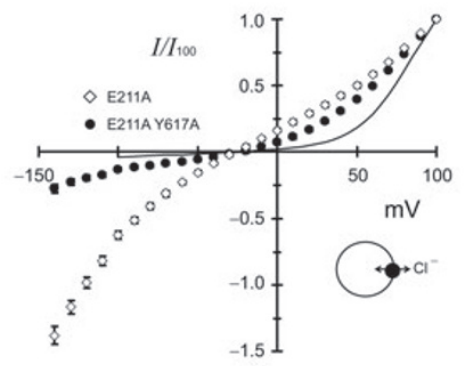

\section{Erratum: Looking ahead with structural genomics}

Nature Structural \& Molecular Biology 14, 1 (2007).

In the version of this Editorial originally published, we incorrectly stated that the Protein Structure Initiative (PSI) represents $~ 1 \%-3 \%$ of the total US National Institutes of Health operating budget. The PSI is funded by the US National Institute of General Medical Sciences (NIGMS) and is allocated $\sim 3 \%$ of the NIGMS annual operating budget. We apologize for this mistake. 